\title{
"What Works" Literature, How Is That Reflected in Juvenile Justice Policies in Albania?
}

\author{
PhD. Marinela Sota
}

\author{
University of Tirana, Faculty of Social Sciences, Department of Social Work and Social Policies
} Email: sotamarinela@yahoo.com

\author{
Doi:10.5901/ajis.2015.v4n2s2p134
}

\section{Abstract}

The principles of "What works" literature are based on theory, practice and research and they bring evidence on successful interventions in different contexts and specifically in juvenile justice policies. "What works" literature in the field of juvenile justice in Albania is not taken in consideration in none of the stages of criminal justice, including investigation, security measures, trial and criminal sentence, the execution of criminal sentence. Ministry of Justice has not developed yet a Strategy for Juvenile Justice to address the minor's problematic facing the criminal justice system. The plan of Action for Children 20122015 has some objectives not achieved yet regarding the minors in conflict with law. The amendments of Code of Criminal Procedures regarding the minors, in force in 2014, has not yet produced positive effects on the minors in conflicts with law in Albania. The role of General Prosecution Office and the court system in this aspect are of great importance for the investigation stage, trial and the execution of the sentence. The discussion presents the principles of literature "What works" in the field of juvenile justice and in this frame suggestions will be presented in line with Criminal Code and Code of Criminal Procedures.

Keywords: juvenile justice, "what works" literature, criminal justice system.

\section{Introduction}

The principles of literature "What works" are based on the theory, practice and research. They provide evidence of successful interventions in different contexts, and especially in youth crime policies.

"What works" literature in the field of juvenile justice is not considered in any of the stages of criminal proceedings, including investigation, security measures, the judgment and the type of punishment, execution of criminal punishment.

The Ministry of Justice has not yet developed a Strategy for Juvenile Justice to address the problems of the criminal justice system for juveniles. The Action Plan for Children 2012-2015 has several objectives that are not made with regard to children in conflict with the law. The amendments of Code of Criminal Procedures, in force in 2014, have not yet produced positive effects. The role of General Prosecution Office and the court system in this aspect are of great importance for the investigation stage, trial and the execution of the sentence.

\section{The role of the state and its policies to reduce juvenile recidivism}

Heike Jung (2003) emphasizes that criminal legislation that emphasizes safety and strong state is counterproductive. Jung says that "the consequences of this approach are social exclusion and feelings of lack of security" (Jung, 2003).

There are two approaches in the criminal literature about social exclusion and crime, an approach that sees crime as a result of social exclusion and the other approach sees social exclusion as a result of crime or as a product of crime control model ${ }^{1}$ (Levay, 2003 ).

The approach sees crime as a result of social exclusion based on the results of studies regarding the type of acts committed, which are primarily offenses against property and in relation to offenders who are minors or adult recidivists (Levay, 2003).

In studies that are based on the approach that social exclusion is a result of the crime, is noted the link between involvement in criminal proceedings and the type of social exclusion penalty for ex-convicts after the first sentence (Bradley, 2001).

\footnotetext{
1 The crime control model focuses only on the punishment of suspected perpetrators of criminal acts without regard to process and procedural guarantees for the accused (explanation of the author).
} 
Despite differences in approach, legislation, processes and practices of different systems for minor offenses, there is a common position that policies to reduce the recidivism of juveniles should be a combination of criminal policies and social welfare policies. Risk and protection factors model is a model that requires a combination of policies aimed at increasing the protection factors through welfare policies and reduction of risk factors through criminal policies.

Type of penalty applied for the first time in a juvenile is related to his recidivism in many studies, for example, sentencing, putting to the test drifts to resentencing more than other penalties, such as a fine (Cain, 1996).

Other factors associated with recidivism are the age when the crime was committed, the age of his first appearance before the court, the offense committed, gender, stay in custody, etc.

In connection with the criminal policy for juveniles it should be taken into account that the population of juvenile offenders is not homogeneous and that it should not be expected that for all it will work a single rehabilitation program (Sechrest, White and Brown, 1979).

Certainly they need to focus interventions to minors who have more risk factors for recidivizim because in this way "if a group of children at high risk for recidivism are identified early and effective interventions to reduce recidivism are made, it affects many the level of crime (Tarling, 1993, quoted by Hagell \& Newburn, 1994).

Studies made by Coumarelos (1994) and Coumarelos \& Weatherburn (1995) have shown that the appropriate intervention for minors who have committed the first offense is to avoid the criminal justice system and support the rehabilitation programs, while more attention should be directed towards the repeater minors, so they say, "If we do nothing against juvenile offenders for the first time, but only advise them, it is certain that most of them will not fall more in trouble with the law; if we send these juveniles to court to get prison sentences or alternative sanctions we will not spend money effectively; on the other hand, if we do nothing for repeaters, but simply send to the court and close them in prison, it is certain that most of them will return; seeing the two groups, recidivist are the ones who seek our attention "(Coumarelos \& Weatherburn, 1995).

Speirs (1988) found that $69 \%$ of young people who had gone to court twice before the age of 15 continued the criminal activity, $80 \%$ of those who went three times was resentenced and $93 \%$ of those who had gone eight times in court were arrested. It seems that it is extremely important the identification of minors who may be recidivists because this inventory will help sections of the juvenile court and social care system in the decision on punishment or placement in social care system.

\subsection{Policies for recidivism: definition}

Cunneen \& Luke (2007) say that the factor that has brought special attention to measuring recidivism is to increase public sector demand for measurable results and that the rate of recidivism is a transparent and universal measure of criminal justice institutions.

Juvenile justice institutions are deemed successful or not based on the level of recidivism that represent minors who commit crimes or offenses after first involvement in the juvenile justice's system. Preventing recidivism is not only the duty of the justice system for minors, however, is an already accepted expectation that juvenile justice institutions prevent recidivism through rehabilitation of convicted minors. (CJCA, 2009).

Measuring recidivism serves to 3 main purposes:

1. To provide information for policy makers to assess the achievement of the objectives of institutions / services and to examine the consequences of changes made to policies or programs targeting juvenile crime;

2. To serve as an indication in the communication to increase the resources required to document the achievement of objectives or to show improvement of the situation;

3. To serve as an indicator for the evaluation of various programs in the system of juvenile justice (CJCA, 2009).

The need to standardize the measurement of recidivism is referred to in early 1970. Thus, NACCJSG (1976) in the US has stated that:

"A major problem for the research is the lack of standardized definitions. Confusion over definitions not only has prevented communication between researchers and professionals in practice, but did not allow comparisons and repeated scientific studies on time".

Standardization of the definition and measurement of recidivism is needed to clearly communicate the results of the study, the method used, to repeat the conceptual model of the study, to enable comparisons between studies and regions and to facilitate the development of knowledge in the field (CJCA, 2009).

Measurement of juvenile recidivism is affected by many factors such as: legislation, for example, the age specified 
in legislation to be considered a child; aftercare services quality; changes in police practices in different regions; changes in the use of arrest and punishment policies; the time of transferring the juveniles in the system for adults in prisons.

Different social factors also affect the level of recidivism in different jurisdictions. These factors include economic and cultural changes, urban or rural area, support for education, family and health in these areas. Communities that are economically disadvantaged and lack the social capital have higher levels of delinquency and crime (Sampson \& Groves, 1989).

\subsection{Policies to reduce youth delinquency as a global concept}

States, more and more are trying to adapt international rules to structure the behavior of all states with regard to the special treatment of children, including minors who commit crimes (Haines, 2000).

Geneva Declaration on the Rights of the Child (1924) claims that to children should be paid special attention.

UN Standard Minimum Rules for the Juvenile Justice Administration² (the Beijing Rules, 1985) claim that the main purpose of a juvenile justice system should be the promotion of the welfare of minors and criminal proceedings should be conducted in the highest interest of the child.

United Nations Convention on the Rights of the Child, which is binding on signatory states determines the prevailing consideration of any policy or decision by states and their institutions, that is the best interest of the child. In its article 3 of the Convention states that:

"In all actions concerning children, whether undertaken by public institutions or private social care, by courts, administrative authorities or legislative bodies, the best interests of the child shall be a primary consideration."

Normalization ${ }^{3}$ and social inclusion are two of the fundamental principles on which should be based all interventions against juvenile offenders (OSCE, 2009). Interventions aimed at social inclusion impact on social risk factors for crime, which states the criminological perception that "effective social policies are the best policies offense" (Levay, 2007).

Basic concepts outlined in international conventions that shape positive practices in juvenile justice are: a) interventions should be in the best interests of the child; b) should avoid programs focused on offense or their authors; $c$ ) work with juveniles should be based on knowledge and experience gained during the practice; $d$ ) the practice should be guided by the principle of normalization and promotion of social inclusion (OSCE, 2009).

International documents in the field of juvenile justice are: the European Convention on Human Rights ${ }^{4}$, the European Convention on the Rights of the Child ${ }^{5}$, the Convention on the Rights of the Child and the UN Standard Minimum Rules for the Administration of Juvenile Justice (Rules Beijing), the UN Guidelines for the Prevention of juvenile Delinquency (the Riyadh Guidelines) and the UN Rules for juveniles deprived of their liberty.

Recommendation CM / Rec (2008) 11 of the EC "on the European Rules for juvenile offenders subject to sanctions or measures"6 aims to harmonize laws on the rights and welfare of minors, offenders, and to promote the development of justice system in the interests of minors in EC member states.

Under this recommendation, sentences or measures provided for minors and ways of their implementation should be based on principles of social integration, education and prevention of recidivism.

According to this recommendation every juvenile justice system should follow a multi-disciplinary approach and multi-institutional, and to integrate into wider social initiatives for juveniles in order to provide a holistic approach and continuity of care for these infant.

Recommendation "new road to face juvenile crime and the role of Juvenile Justice ${ }^{7}$ (2003) EC urges States in the application of legislation, policies and practice en accordance with new developments in juvenile justice. This

2 The Beijing Rules are not binding on member states of the UN, but are recommendations for these countries (explanation of the author).

${ }^{3}$ Normalization is seen as a process that integrates interventions and activities for minors with problems in the wide range of interventions and activities for children (Haines, 2009)

${ }^{4}$ Ratified by RA on 10.02 .1996

${ }^{5}$ Ratified by RA on 19.10 .2011

${ }^{6}$ Adopted by the Committee of Ministers on 5 November 2008

${ }^{7}$ Adopted by the Committee of Ministers on 24 September 2003 
Recommendation in the strategic approaches (Part II, Section 2) states that systems of juvenile justice should aim: a) preventing crime and recidivism; b) re-socialization and reintegration of prisoners; c) addressing the needs and interests of victims of criminal acts. On this point, it is suggested that the system of juvenile justice should be seen by the states, the public and the media as an integral part of community-based interventions for the prevention of crime that takes into account family, school, community and peers, contexts where happens violation of the law.

The recommendation above suggests new answers to the delinquency of minors (Part III, item 19), among which says that the preparation for the release of juvenile offenders starts from the first day of the punishment. Needs assessment and risk should be the first step to prepare the inmate for release by addressing in a coordinated manner with other services, it needs to education, income, health services, housing, supervision, family and a suitable environment social.

This recommendation in Part IV, which contains suggestions for the implementation of policies to reduce juvenile delinquency, point 21 , states that responses to juvenile delinquency should be planned, coordinated and provided by collaborating institutions at central and local government, including police, probation, prosecution and court, child protection services and other care services, educational institutions, employment services, health services and housing services.

The Council of Europe has also issued other recommendations in the field of juvenile delinquency as such Recommendation 1987 (20) for social action against juvenile delinquency, Recommendation 2000 (20) The role of early intervention to prevent psycho-social crime and Recommendation 2008 (11) European Rules for Juveniles convicted or on remand.

\section{Theoretical paradigms for the control of juvenile crime}

Knowledge of theoretical paradigms serves two purposes. They help to better explanation of juvenile crime and also serve as a guide for policymakers, employees of juvenile justice and care system in their attempt to discontinued criminal conduct, to enhance positive opportunities for minors at risk and to create a society that adequately meets the needs of all children.

\subsection{The paradigm of termination}

The paradigm of termination is a method that aims to reveal what stops individuals from committing more offenses. This paradigm does not focus on the type of intervention of the prisoners, but sees intervention as supporting the process of termination and not as a treatment that corrects the behavior of the convict.

Maruna (2001) mentions three theoretical perspectives where is based the termination. According to Maruna these theories are: reform of maturity, social relations theory and narrative theory. These theories have in common the condition that the individual may terminate criminal activity if he wins things in life that make you reassess life with a new approach. Termination paradigm assumes that the individual is not enough to place changes to avoid being involved in recidivism, but that these changes should be significant to.

Termination of criminal activity is defined on two levels: primary level and secondary level. The primary level is the achievement of a period during which no criminal offense is committed; and secondary level is the benefit of a new individual identity as a former convicted.

Maruna stresses the importance of identity and self image. He distinguishes two types of inmates in a study for recidivist convicts: the permanents and the circuit breakers. The permanents, the prisoners who did not stop the criminal activity, described themselves as criminals with a life controlled by an external force, and the circuit breaker, the prisoners who were not involved in the criminal acts, saw themselves capable to renounce with the help of some outside factors.

Termination paradigm emphasizes the importance of accredited programs and the integrity of these programs, and other subsequent studies have recognized and accepted the importance of the relationship between young offenders and supervisors (officer in charge to supervise the convict during the first sentence ${ }^{8}$ ) for the termination process (Raynor, 2004).

${ }^{8}$ Supervisory employee may be prison / detention who is in charge of the child, probation officer, or other professionals outside the criminal justice system (explanation of the author). 


\subsection{The model of risk factors and protection factors}

The model of risk factors and protection factors can be conceptualized as secondary prevention for intervention aims to reduce the possibility of repeating criminal behavior among young people who have committed a crime and have at least one criminal conviction by imprisonment or community (Klein, Alexander, \& Parsons, 1977).

The model of risk factors and protection factors developed by Catalano \& Hawkins (1996) suggests that the purpose of the prevention activities should be the reduction of risk by increasing protection.

This prevention model is a synthesis of three existing theories in criminology, social control theory (Hirschi, 1969), social learning theory (Akers \& Burgess 1966) and the theory of differential association (Sutherland \& Cressey 1978).

This model embodies the results of studies conducted on risk factors and protection factors related to crime and age a development perspective, the analysis of environmental factors and the ways of learning socializing behavior. The model is based on the theoretical assumption that children learn behavior (Arthur, Hawkins, et al., 1994).

The development of a system of juvenile justice based on the model of risk factors and protection factors creates important prerequisites for prevention of recurrence of the offense based on thorough assessment of the child's needs seen by the ecological perspective (Bronfenbrenner, 1986), which it underlines the combination of different factors areas.

\subsection{The model of counseling and evaluation of minors}

The model of counseling and evaluation of minors sees juvenile criminal behavior as a result of variables related to a) the individual characteristics of the child (eg. Genetic predisposition and / or heritage, gender, personality and intelligence aspects, social skills and life abilities, factors of cognitive process); b) ecological context where the child resides (eg. family, peers, school and community) and c) a combination between these variables.

This model in particular highlights the importance of identifying risk factors and protection to help increase the minor resilience that he / she can use their potentials to cease involvement in crime succeeding and winning important things for his / her life.

Similarly to the pattern of the risk and protection model and to the minors counseling and evaluation model there are created other models connecting crime with variables of family sphere, peers, school results, specific age, community and environment (Simcha-Fagan \& Schwartz, 1986; Henggeler \& Borduin, 1990; Patterson, Capaldi, \& Bank, 1991).

\section{Conclusions}

Despite differences in approach, legislation, processes and practices of different systems for minor offenses, there is a common position that policies to reduce the recidivism of juveniles should be a combination of criminal policies and social welfare policies.

Basic concepts outlined in international conventions that shape positive practices in juvenile justice are: a) interventions should be in the best interests of the child; b) should avoid programs focused on offense or their authors; $c$ ) work with juveniles should be based on knowledge and experience gained during the practice; $d$ ) the practice should be guided by the principle of normalization and promotion of social inclusion.

Knowledge of theoretical paradigms serves two purposes. They help to a better explanation of juvenile crime and also serve as a guide for policymakers, employees of juvenile justice and care system in their attempt to disrupt criminal behavior, to enhance positive opportunities for minors at risk and to create a society that adequately meets the needs of all children.

\section{References}

Bradley, T. 2001, Social Exclusion, The Sage Dictionary of criminology, London, Sage

Bronfenbrenner, U., 1986, Ecology of the family as a context for human development: Research perspectives. Developmental Psychology, 22(6). 723-742

CJCA, 2009, Defining and measuring recidivism, www.cjca.net

Haines. K, 2000, Referral Orders and the New Youth Justice, në OSCE 2009, Manual për Punonjësit e Shërbimit të Provës, Pegi, Tiranë Hawkins J.D, Catalano,R.E., Miller,J.Y., 1992, Risk and protective factors for alcohol and other drug problems in adolescence and early adulthood: Implications for substance abuse prevention, Psychological Bulletin, 112, 64-105

Jung, S. 2003, Risk-need assessment of juvenile offenders, Criminal Justice and Behavior, 26, 69-89

Klein,N.C, Alexander, J.F\&Parsons,B.V, 1977, Impact of family systems intervention on recidivism and sibling delinquency: A model of 
primary prevention and program evaluation, Journal of Consulting and Clinical Psychology, 45, 469-474

Maruna, 2001, quoted from Deering J. 2009. Manual probation officer, OSCE, Pegi, Albania

NCJRS, 2003, Child Delinquency, www.ojjdp.ncjrs.org

Patterson, G.R, et al, 1998, Variables that initiate and maintain an early-onset trajectory for juvenile offending, Development and Psychopathology, 10, 531-547

Plan of Action for Children, 2012-2015

Recommendation 12 "new road to face juvenile crime and the role of Juvenile Justice (2003) EC

Recommendation 1987 (20) for social action against juvenile crime.

Recommendation 2000 (20) The role of early intervention psychosocial for crime prevention.

Recommendation 2008 (11) European Rules for Juveniles convicted or on remand.

Recommendation CM / Rec (2008) 11 of the EC "on the European Rules for juvenile offenders subject to sanctions or measures"

Standard Minimum Rules for the Administration of Juvenile Justice (the Beijing Rules)

UN Guidelines for the Prevention of Juvenile Delinquency (the Riyadh Guidelines)

UN Rules for juveniles deprived of their liberty.

Simcha-Fagan, O. \& Schwartz, JE, 1986, Neighborhood and delinquency: An Assessment of contextual Effects, Criminology, 24, 667699

\section{Internet resources}

www.drejtesia.gov.al

www.ligjet.org

www.pp.gov.al 